\title{
Л.В. КЛИМОВИЧ
}

\section{ОБРАЗОВАНИЕ И РАЗВИТИЕ «СОЮЗА РУССКОГО СОКОЛЬСТВА» В ЭМИГРАЦИИ В 1920-1930-е ГОДЫ}

Ключевые слова: история России, эмиграция, молодежь, «Союз русского сокольства», молодежные организации, зарубежная Россия.

Статья посвящена анализу деятельности «Союза русского сокольства» в эмиграции в 1920-1930-е г2. Оказавшись в эмиграции молодые люди были вынуждены адаптироваться к новым условиям, при этом не потерять жизненные ориентиры. Особую роль в социализации подрастающего поколения и сохранении его связи с потерянной родиной сыграли молодежные движения и объединения. Наиболее активно сокольское движение в эмиграции развивалось в Чехословакии и Королевстве Югославия. На основе анализа архивных и опубликованных источников с помощью общенаучных методов проведен анализ деятельности «Русского сокола» в Чехословакии, "Русского сокола» в Королевстве сербов, хорватов и словенцев, показаны причины создания «Союза русского сокольства».

В исследовании подчеркивается, что участие подрастающего поколения российских эмигрантов в деятельности сокольских объединений способствовало сохранению их национально-культурной идентичности, ощущению причастности к русской истории и русскому народу. Отмечено, что «Союз русского сокольства» проводил такие мероприятия для местного населения, как выставки, на которых можно было познакомиться с историей организации, узнать о русских традициях и установить взаимоотношения между эмигрантской молодежью и местными жителями. Анализ источников продемонстрировал единую структуру сокольских объединений, строгие правила приема. Проанализированные практики работы с подрастающим поколением в сокольских объединениях сочетали в себе физическое развитие и воспитание молодежи в любви к родине, способствовали формированию национально-культурной идентичности. Распространяя свою деятельность не только на лиц старше 18 лет, но и на подростков, сокольское движение помогало занять свободное время молодого человека, культивировало интерес к учебе и спорту, что содействовало ограждению молодежи от влияния «улицы».

В 1918-1922 гг. за рубежом оказались тысячи эмигрантов из России. В 1920-е гг. эмиграция сохраняла подвижность, и места расселения беженцев менялись. Через пограничные страны и Константинополь эмигранты переезжали в Балканские страны, Францию, Германию и Чехословакию. Для молодого поколения этот выбор зависел от возможности получить или продолжить образование, той поддержки, которую оказывали правительства принимающих стран русским беженцам. К концу 1920-х - началу 1930-х гг., когда надежда на возвращение в Россию исчезла и встала необходимость устраивать постоянную жизнь в странах-реципиентах, выбор места жительства обуславливался благополучной экономической и социальной инфраструктурой [1. С. 46].

Оказавшись в чужой стране, молодые эмигранты были вынуждены адаптироваться к новым условиям, при этом не потерять жизненные ориентиры. 
Особую роль в социализации подрастающего поколения и сохранении его связи с потерянной родиной сыграли молодежные движения и объединения. Истоки молодежных организаций лежат в дореволюционной России, где они создавались по инициативе царского правительства. В первые десятилетия XX в. действовали: Союз русских соколов, Русские скауты, Христианский союз молодых людей, Российский союз монархической молодежи.

«Союз русских соколов» был первой фрормой самоорганизации русской молодежи. Он получил широкое признание и государственную регистрацию своих документов. Русские соколы воспитывались на основе верности своему народу и своими задачами ставили: «1) фризическое и духовное воспитание русских людей, поддержание в них бодрости; 2) борьбу с денационализацией; 3) создание кадровых русских сокольских деятелей» [8]. Будучи преимущественно организацией «мужской» молодежи старше 18 лет, Союз русских соколов понес большие потери в Первой мировой войне. В 1922 г. он был запрещен в Советской России.

Целью исследования выступает изучение процесса становления и деятельности «Союза русского сокольства» за границей в 1920-1930-е гг.

Статья базируется на основных общенаучных методах. Историко-событийный анализ позволил выяснить причины появления сокольских объединений русских эмигрантов, субъективно-деятельностный анализ, основанный на интерпретации и фиксации поведенческих актов людей, на выяснении того смысла, который они вкладывают в свои поступки, помог увидеть внутренние противоречия в «Союзе русского сокольства».

Части сокольского движения удалось эмигрировать и восстановить свою деятельность на чужбине. Организация «Русский сокол» свою историю в эмиграции берет с начала 1920-х гг. В основе объединения молодежи лежало воспитание в русских традициях, физическое и духовное развитие [14. С. 18]. Физическая подготовка строилась на сокольской гимнастике, разработанной в середине XIX в. чехом Мирославом Тыршем. Система фризического воспитания впервые была использована как символ свободы славянских народов, олицетворяла независимость и мужество. В сокольской гимнастике упор делался на эстетичность и завершенность гимнастических упражнений. Широкое распространение и поддержку общество «Русский сокол» получило в Чехословакии и Королевстве Югославия, где были сильны местные сокольские организации. Гимнастическое общество «Русский сокол» в Праге в уставе 1923 г. озвучило свои цели: «целью общества является нравственное и физическое развитие русского народа в духе идей основателей сокольства Тырша и Фюгнера» [2. Д. 23. Л. 3].

Занятия гимнастикой и другими видами спорта, туристические походы, участие в летних лагерях привлекали подрастающее поколение российских эмигрантов. Большое внимание уделялось воспитанию молодежи в национальном духе. Эта цель достигалась посредством чтения лекций по истории России, изучению русских предметов - русского языка, русской истории, русской географии, Закона Божьего. Совместное отмечание православных праздников и церковных событий способствовало фрормированию национальнокультурной идентичности эмигрантской молодежи.

Особое внимание молодежные организации уделяли членству и вопросу вступления в организацию. Членом организации мог стать человек, достигший 
18 лет, славянской народности, разделявший идеи сокольского движения [9. С. 29], но подростки, не являясь полноценными членами организации, принимали участие в сокольских мероприятиях и занятиях гимнастикой [2. Д. 23. Л.4]. Кроме того, желающие вступить в сокольскую организацию должны были иметь двух поручителей из числа действующих членов сокольских объединений [10. С. 350].

Прием в Сокольское общество осуществлялся по личному заявлению. Заявление рассматривалось на заседании Совета общества и голосованием решался вопрос: принять или не принять того или иного кандидата. Получивший положительное решение принимался на испытание и еще не пользовался всеми правами члена. Испытания включали в себя прослушивание лекций и выполнение гимнастических упражнений. Лекции касались вопросов сущности и истории сокольского движения, его организации, был включен специальный курс о здравоведении [9. С. 33]. Для кандидатов в члены организации предусматривался испытательный срок 6 месяцев, во время которого необходимо было выполнять все обязанности и задачи сокольского движения [2. Д. 23. Л. 4]. Иногда срок мог достигать одного года. От прохождения испытания освобождались лица, перешедшие из других сокольских обществ [9. С. 34].

Принятие в организацию сопровождалось принесением присяги и сдачей экзамена на знание сущности сокольского движения. В тексте присяги были слова, которые вероятно, сложно было произносить молодым людям, многие из которых не знали и не помнили России, так как уехали из нее в раннем возрасте. «Обещаюсь всегда всеми силами защищать свою родину, быть готовым принести за ее благо в жертву даже жизнь свою в борьбе со всеми, кто какимлибо образом посягнет на ее честь, безопасность и самостоятельность» именно этими словами завершался текст присяги на членство в гимнастическом обществе «Русский сокол в Праге» [12]. Россия осталась у них только в памяти, в тех образах, которые транслировали им взрослые. В «Русском соколе» молодым людям преподавалась история и культура России, рассказывалось о национальных традициях, природных богатствах России.

Для «Русского сокола» в Чехословакии критичным был 1928 год, когда русская эмиграция покидала страну: молодежь в основном получила образование и отправилась в поисках лучшей работы, найти которую в Чехословакии было сложно из-за введения в действие закона, ущемляющего в правах мигранта при приеме на работу.

Гимнастическое общество «Русский сокол» в Королевстве сербов, хорватов и словенцев (Королевство СХС) действовало уже в 1921 г., его переписка с Державной комиссией по делам русских беженцев в Королевстве СХС (далее Державная комиссия) свидетельствует, что они получали от нее ассигнования, в том числе для участия в сокольских слетах [3. Д. 71. Л. 1-7]. Например, в августе 1922 г. было выделено 3000 динаров на поездку 50 членов «Русского сокола» из Белграда для участия во Всеславянском слете соколов в Любляне [3. Д. 71. Л. 1], а также 8000 динаров на покупку обмундирования и организацию предстоящих выступлений общества «Русский сокол» в Земуне [3. Д. 71. Л. 12]. Такая же сумма была выделена и «Русскому соколу» в Любляне [3. Д. 71. Л. 15]. Эти местные отделения входили в состав «Русского сокола» в Королевстве СХC, но при этом ассигнования получали отдельно. 
Стоит отметить, что позже в 1930-е гг. Державная комиссия выделяла помощь русским сокольским организациям в Королевстве Югославия уже в виде ссуд. Так, в фреврале 1930 г. была выдана сумма в 4000 динаров сроком на 8 месяцев с ежемесячным платежом 500 динаров [3. Д. 99. Л. 2]. Анализ корреспонденции Державной комиссии демонстрирует, что долг возвращался нерегулярно, и на 17 июня 1931 г. была задолженность 3300 динаров [3. Д. 99. Л. 4]. Несмотря на это, в 1932 г. была вновь выдана ссуда под коллективное поручительство в размере 4500 динаров [3. Д. 99. Л. 4] для участия в Всесокольском слете в Праге [3. Д. 99. Л. 8]. Долг постепенно копился, это подтверждает напоминание Державной Комиссии 26 октября 1932 г. о необходимости погасить первую задолженность в сумме 2800 динаров и «приступить к погашению второй заимообразной ссуды, выданной в июне 1932 г. на сумму 4500 динаров» [3. Д. 99. Л. 12]. К 1935 г. на территории Королевства Югославия действовало 25 русских сокольских организаций, к 1938 г. - 28 во всех крупных городах [10. C. 351].

Русские сокольские организации существовали практически во всех центрах русской эмиграции, имелись ячейки в русских школах и кадетских корпусах. Во Франции организации русских соколов были малочисленны и менее активны, чем в Чехословакии и Королевстве СХС. Наиболее крупное объединение «Русский сокол», основанное в 1927 г., было в Медоне. В декабре 1927 г. создан «Русский сокол» в Ницце, его возглавлял бывший староста «Союза русского сокольства» в России А.С. Гижицкий. Организация для проведения занятий пользовалась залом, предоставленным Французским гимназическим обществом, и через два года насчитывала 45 действительных членов [16. С. 11]. В Болгарии «Русский сокол» получил организационное оформление только в 1927 г. с центром в Софии.

На учредительном съезде сокольских организаций из Чехословакии и Королевства СХC в декабре 1923 г. был создан «Союз русского сокольства». Членский билет включал отметку о том, в каком обществе человек состоял [5. Д. 634. Л. 6].

Основными задачами «Союз русского сокольства» ставил распространение сокольской идеологии и сплочение молодежи из эмигрантской среды. Организация заявляла о своей аполитичности, но при этом разрешала принимать своим членам участие в политической жизни страны, «политическим спорам нет места в сокольне, ибо это нарушает братское единство всех соколов и вредит самой идее сокольской» [4. Д. 258. Л. 8].

Активная работа «Союза русского сокольства» позволила провести в июле 1924 г. Слет «Русских соколов» за границей [13. С. 223]. В 1926 г. Советом «Союза русского сокольства» основано издательство «Русская сокольская матица» ${ }^{1}$, в нем печаталась литература для сокольских организаций.

Например, в 1926 г. была издана сокольская книжка «Как основать и вести гимнастическое общество “Русский сокол”», в которой приведена инструкция

\footnotetext{
1 «Матица» - название национальных культурно-просветительных обществ, созданных рядом славянских народов в эпоху их национально-культурного возрождения в XIX в. (Матица галицко-русская - галицко-русское культурно-образовательное общество (1848 г., г. Львов, Матица моравская (чеш. Matice moravska) - моравское культурно-просветительское общество (1852 г., г. Брно), Матица чешская (чеш. Matice česká) - чешское культурно-просветительное общество (1831 г., г. Прага), и др.).
} 
по организации местной сокольской организации с нуля. Отметим, что встречается рекомендация вступать сначала в «инославянское сокольское общество» [2. Д. 23. Л. 49об.], если оно существует, там формировать русскую дружину и потом уже отделяться как самостоятельное общество «Русский сокол».

Создавать сокольские общества в разных городах и странах необходимо было со схожим названием, например гимнастическое общество «Русский сокол» в Париже, гимназическое общество «Русский сокол» в Праге и т.д. Устав общества следовало утверждать в соответствии с требованиями местного законодательства, а вести внешние сношения на русском языке. Каждому обществу предписывалось иметь свой бланк для переписки, на штампе которого отражалось название общества, указание его местопребывания, дата и номер исходящего документа. Единые требования делали процесс создания общества в разных городах и странах более понятным и четким. Текущее руководство общества осуществлял Совет, при этом разные функции должны выполнять как можно большее количество человек: «нужно стремиться в Совете использовать, насколько это возможно, равномерно всех членов Совета, в особенности не забывать молодых членов-новичков, заботиться таким образом, о вышколении подрастающих сокольских деятелях» [9. С. 15-16].

Брошюра «Как основать и вести гимнастическое общество "Русский сокол"» являлась методическим руководством для создания сокольских обществ по единой схеме: в ней отражены вопросы регистрации устава, приема новых членов, исключения членов, регламентация проведения заседаний Совета общества и его полномочия.

Составители отмечали, что русские часто пренебрегают правилами, систематичностью, надеются на «авось», и «потому плетутся в хвосте тех, кто работает продумано и систематично и настойчиво... Одной из насущных задач Русского сокольства и является как раз беспощадная борьба с этим чисто «внутренним» врагом - “авось, небось, как-нибудь, кривая вывезет и ничего!"» [9. C. 95].

На VIII всесокольском слете состоялся III съезд «Союза русского сокольства» в июле 1926 г., на котором были выбраны комиссии для разработки нового Устава, текста Русской сокольской присяги, Сокольского русского значка [15. С. 92-93], принято решение о вхождении «Союза русского сокольства» в «Славянский сокольский союз» [13. С. 224].

Установление контактов с принимающим сообществом и желание рассказать о своей деятельности, не только эмигрантам, но и коренным жителям вылились в устройство Русской сокольской выставки. Она открылась 2 июля 1926 г. в Праге и включала в себя экспонаты по истории сокольского движения в России до 1917 г., награды, дипломы, фотографии русских сокольских организаций из Чехословакии и Королевства СXC, печатные материалы, вырезки из газет, периодические издания «Союза русского сокольства». За период со 2 по 20 июля выставку посетило около 20 тысяч человек [11. С. 3]. «Союз русского сокольства» в 1930-е гг. испытал на себе трудности, как и другие эмигрантские организации: финансирование со стороны правительств принимающих стран сократилось, надежды на возвращение в Россию рассеялись. 26-27 декабря 1930 г. был проведен IV съезд «Союза русского сокольства» в Праге, председатель съезда профессор С. Острогорский передал в адрес короля Югославии «искреннейшие приветствия и засвидетельствовал чувства глубочайшего уважения» [6. Д. 107. Л. 40]. 
Все эти обстоятельства привели к тому, что в 1932 г. на V съезде «Союза русского сокольства» прозвучало предложение перенести центр из Праги в Белград, аргументируя это большей численностью «Русского сокола в Королевстве Югославия». Когда эта инициатива не получила поддержки, часть делегатов русских сокольских обществ из Югославии покинули зал заседаний [17. С. 17]. Несмотря на то, что предложение не было принято на съезде, в конце 1932 г. центр «Союза русского сокольства» переместился в Белград [7. C. 30]. Противостояние между двумя центрами: старым в Праге и новым в Белграде только нарастало, выражаясь открыто на страницах периодических изданий: «...этому мешали многочисленные полномочные и самозванные представители Белградского Союза в Праге, которые всюду лезли, везде бестолково вмешивались» [18. С. 3]. Эти события закономерно привели к распаду «Союза русского сокольства» в 1938 г.

Анализ деятельности сокольских организаций русских эмигрантов позволяет выделить успешные практики работы с подрастающим поколением, сочетающие в себе гармоничное физическое развитие с воспитанием молодежи в любви к родине. Материалы статьи придадут импульс для дальнейших научных исследований, позволят по-новому взглянуть на многие проблемы истории и культуры российской эмиграции.

Выводы. В эмиграции возродились молодежные объединения дореволюционной России, деятельность организаций «Русских соколов» тому подтверждение. Организационные основы в разных странах были схожи и позволяли унифицировать систему управления и внешних сношений. Распространяя свою деятельность не только на лиц старше 18 лет, но и на подростков, сокольское движение способствовало сохранению национально-культурной идентичности молодежи, помогало занять свободное время молодого человека, культивировало интерес к учебе и спорту, что содействовало ограждению молодежи от влияния «улицы».

\section{Литература}

1. Бочарова 3.С. «...Не принявшие иного подданства»: проблемы социальноправовой адаптации российских эмигрантов в 1920-1930-е гг. СПб., 2005, 251 с.

2. Государственный архив Российской Федерации (далее - ГАРФ). Ф. 6025. Оп. 1.

3. ГАРФ. Ф. 6792 . Оп. 1.

4. ГАРФ. Ф. 7055. Оп. 1.

5. ГАРФ. Ф. 10055. Оп. 3.

6. ГАРФ. Ф. 10113. Оп. 1.

7. Гусаченко А.С. Движение «Сокол» в контексте русской эмиграции в Латвии в 2030-х годах XX века // Вопросы исторической науки: материалы IV Междунар. науч. конф. (г. Москва, ноябрь 2016 г.). М.: Буки-Веди, 2016. С. 23-36.

8. Деркаченко П. Русское молодежное движение и советский комсомол: 19051937 // Русский мир. 2002. № 6. С. 30-64.

9. Как основать и вести гимнастическое общество «Русский сокол». Издание «Русской сокольской матицы». Прага, 1926. 96 с.

10. Лушин М.М. «Русский сокол» в Югославии // Столетие двух эмиграций 19192019. М.: Институт славяноведения РАН. 2019. С. 345-360.

11. Обзор русской сокольской жизни // Прага. 1926. № 15, 15 авг.

12. Присяга членов гимнастического общества «Русский сокол в Праге» // Národni Archiv České republiky. F. 463. Ka. 35. Inv. 153.

13. Русские в Праге, 1918-1928 гг. / ред.-изд. С.П. Постников. Прага: [Б. и.], 1928. $343 \mathrm{c}$. 
14. Русский сокольский вестник. 1927. № 2.

15. Русский сокольский вестник. 1927. № 6-7.

16. Русский сокольский вестник. 1931. № 3.

17. Русский сокольский вестник. 1932. № 4-5.

18. Русский сокольский вестник. 1938. № 8.

КЛИМОВИЧ ЛЮДМИЛА ВАЛЕРЬЕВНА - кандидат исторических наук, доцент кафедры истории, Ульяновский государственный педагогический университет имени И.Н. Ульянова, Россия, Ульяновск (Lusek84@yandex.ru, ORCID: https://orcid.org/00000003-3541-7159).

\section{Liudmila V. KLIMOVICH \\ FORMATION AND DEVELOPMENT OF THE "UNION OF THE RUSSIAN SOKOLSTVO" IN EMIGRATION IN THE 1920s AND 1930s YEARS}

Key words: history of Russia, emigration, the youth, "Union of Russian Sokolstvo", youth organizations, Foreign Russia.

The article is devoted to the analysis of the activities of the "Union of the Russian Sokolstvo" in emigration in the 1920s-1930s. Having found themselves in emigration, young people were forced to adapt to new conditions, while not losing their life orientations. Youth movements and associations played a special role in socialization of the younger generation and preserving its connection with the lost homeland. The most active Sokol movement in emigration developed in Czechoslovakia and the Kingdom of Yugoslavia. Basing on the analysis of archival and published sources and using general scientific methods, the article analyzes the activities carried out by the "Russian Sokol" in Czechoslovakia, the "Russian Sokol" in the Kingdom of the Serbs, the Croats and the Slovenes, and shows the reasons for creating the "Union of the Russian Sokolstvo".

The study emphasizes that participation of the Russian emigrants' oncoming generation in the activities of Sokol associations contributed to preserving their national and cultural identity, the sense of belonging to the Russian history and the Russian people. It is noted that the "Union of the Russian Sokolstvo" held such events for the local population as exhibitions, where it was possible to get acquainted with the history of the organization, to learn about Russian traditions and to establish relationships between the emigrant youth and local residents. The analysis of sources demonstrated a unified structure of Sokol associations, strict admission rules. The analyzed practices of working with the oncoming generation in Sokol associations combined physical development and raising the young people in love to the motherland, contributed to the formation of national and cultural identity. Extending its activities not only to persons over the age of 18, but to teenagers as well, the Sokol movement helped to occupy the free time of a young man, cultivated the interest in studying and sports, which helped to protect young people from the influence of the "street".

\section{References}

1. Bocharova Z.S. "...Ne prinyavshie inogo poddanstva»: problemy sotsial'no-pravovoi adaptatsii rossiiskikh emigrantov v 1920-1930-e gg. ["... Those who did not accept other citizenship": problems of social and legal adaptation of Russian emigrants in the 1920s1930s]. St. Petersburg, 2005, 251 p.

2. Gosudarstvennyi arkhiv Rossiiskoi Federatsii. F. 6025. Op. 1 [State Archives of the Russian Federation. Archive 6025. Anagraph 1].

3. Gosudarstvennyi arkhiv Rossiiskoi Federatsii. F. 6792. Op. 1 [State Archives of the Russian Federation. Archive 6792. Anagraph 1]. 
4. Gosudarstvennyi arkhiv Rossiiskoi Federatsii. F. 7055. Op. 1 [State Archives of the Russian Federation. Archive 7055. Anagraph 1].

5. Gosudarstvennyi arkhiv Rossiiskoi Federatsii. F. 10055. Op. 3 [State Archives of the Russian Federation. Archive 10555. Anagraph 3].

6. Gosudarstvennyi arkhiv Rossiiskoi Federatsii. F. 10113. Op. 1 [State Archives of the Russian Federation. Archive 10113. Anagraph 1].

7. Gusachenko A.S. Dvizhenie «Sokol» v kontekste russkoi emigratsii v Latvii v 20-30kh godakh XX veka [The Falcon Movement in the Context of Russian Emigration in Latvia in the 1920s and 1930s]. In: Voprosy istoricheskoi nauki: materialy IV Mezhdunar. nauch. konf. (g. Moskva, nojabr' 2016 g.). [Proc. of the $4^{\text {th }}$ Int. Sci. Conf. «Problems of Historical Science»]. Moscow, Buki-Vedi Publ., 2016, pp. 23-36.

8. Derkachenko P. Russkoe molodezhnoe dvizhenie i sovetskii komsomol: 1905-1937 [Russian youth movement and the Soviet Komsomol: 1905-1937]. Russkii mir, 2002, no. 6, pp. 30-64.

9. Kak osnovat' i vesti gimnasticheskoe obshchestvo «Russkii sokol». [How to found and run the Russian Falcon gymnastics society]. Praga, 1926, 96 p.

10. Lushin M.M. "Russkii sokol» v Jugoslavii ["Russian Falcon" in Yugoslavia]. In: Stoletie dvukh emigratsii 1919-2019 [Centenary of two emigres 1919--2019]. Moscow, 2019, pp. 345-360.

11. Obzor russkoi sokol'skoi zhizni [Review of Russian Sokol life]. Praga, 1926, no. 15, Aug. 15.

12. Prisyaga chlenov gimnasticheskogo obshchestva "Russkii sokol v Prage» [Oath of members of the Russian Falcon in Prague gymnastics society]. In: Národni Archiv České republiky. F. 463. Ka. 35. Inv. 153 [People's Archives of the Czech Republic. Archive 463].

13. Postnikov S.P., ed. Russkie v Prage, 1918-1928 gg. [Russians in Prague, 19181928]. Praga, 1928, 343 p.

14. Russkii sokol'skii vestnik, 1927, no. 2.

15. Russkii sokol'skii vestnik, 1927, no. 6-7.

16. Russkii sokol'skii vestnik, 1931, no. 3.

17. Russkii sokol'skii vestnik, 1932, no. 4-5.

18. Russkii sokol'skii vestnik, 1938, no. 8.

LIUDMILA V. KLIMOVICH - Candidate of Historical Sciences, Associate Professor of History Department, Ulyanovsk State Pedagogical University named after I.N. Ulyanova, Russia, Ulyanovsk (Lusek84@yandex.ru, ORCID: https://orcid.org/0000-0003-3541-7159).

Формат цитирования: Климович Л.В. Образование и развитие «Союза русского сокольства» в эмиграции в 1920-1930-е годы// Исторический поиск/ Historical Search. - 2021. - Т. 2, № 4. - C. 37-44. DOI: 10.47026/2712-9454-2021-2-4-37-44. 